\title{
Alanine Aminotransferase is a Predictor of NAFLD Activity Score for Diagnosing Non-alcoholic Steatoehpatitis
}

\author{
${ }^{*}$ Das $\mathrm{DC}^{1}$, Alam $\mathrm{SMN}^{2}$, Das $\mathrm{R}^{3}$, Mohsena $\mathrm{M}^{4}$, Mahtab MA
}

\begin{abstract}
Nonalcoholic fatty liver disease (NAFLD) is a metabolic disorder characterized by excessive triglyceride-accumulation in hepatocytes. NAFLD has a multifactorial etiology and a combination of environmental, genetic and metabolic factors play a role in the development of advanced disease. NAFLD consists of a wide spectrum of conditions, ranging from simple steatosis to nonalcoholic steatohepatitis (NASH) which can progress to cirrhosis and hepatocellular carcinoma (HCC). Despite the high prevalence and severity of hepatic illness, NAFLD remains under diagnosed, because of few symptoms, lack of accurate laboratory markers. The accurate diagnosis of NASH remains dependent on specific histological parameters in liver biopsy. Although liver biopsy remains the 'gold standard', there are practical limitations, including costs and risks. There is an increasing requirement for simple, less invasive, highly accurate and affordable screening tools. Alanine aminotransferase (ALT) has been proposed as a noninvasive and available marker for assessment of NASH. A hospital based observational study was carried out for a period of two years in the Department of Hepatology, Bangabandhu Sheikh Mujib Medical University, Dhaka, Bangladesh. Data were analyzed by SPSS version 16. Statistical inference were done by estimating distribution, Chi-square test and student's
\end{abstract}

1. *Dr. Dulal Chandra Das, Medical Officer, Department of Hepatology, Bangabandhu Sheikh Mujib Medical University (BSMMU), Dhaka. E-mail: dulaldas36@gmail.com.

2. Dr. Sheikh Mohammad Noor-E-Alam, Assistant Professor, Department of Hepatology, Bangabandhu Sheikh Mujib Medical University (BSMMU), Dhaka.

3. Dr. Ripon Das, Dental Surgeon, Railway General Hospital, Dhaka.

4. Professor Masuda Mohsena, Department of community Medicine, Ibrahim Medical College, Dhaka.

5. Professor Mamun Al Mahtab, Chairman, Department of Hepatology, BSMMU, Dhaka.

*For correspondence t-test respectively. Fifty (50) patients were analysed. Twenty five were NASH and twenty five were simple steatosis. ALT in NASH group were 97.0 $\pm 51.51 U / L$ and insimple steatosis group were $55.5 \pm 28.6$ IU/L. In NASH group $64 \%$ of raised ALT had NASH. In Non-NASH group $16 \%$ of raised ALT had no NASH. There was significant difference in the NAFLD activity score for diagnosing NASH between elevated and normal ALT( $P$ value 0.001).

Keywords: Nonalcoholic fatty liver disease, Alanine aminotransferase, NAFLD activity score (NAS), Nonalcoholic Steatohepatitis.

\section{INTRODUCTION}

Nonalcoholic fatty liver disease (NAFLD) is a metabolic disorder characterized by excessive triglyceride accumulation in hepatocytes. ${ }^{1}$ NAFLD has a multifactorial etiology and a combination of environmental, genetic and metabolic factors play a role in the development of advanced disease. NAFLD is an acquired metabolic stress-induced liver disease associated with insulin resistance (IR) and genetic susceptibility, sharing histological similarities with alcoholic liver disease (ALD) in the absence of substantial alcohol consumption or other causes of liver disease. ${ }^{2}$ Two broad types are recognizedsimple steatosis is typically stable while non-alcoholic steatohepatitis (NASH) is characterized by significant cell injury and the potential for progression to cirrhosis. ${ }^{3}$ NAFLD consists of a wide spectrum of conditions, ranging from simple steatosis to non-alcoholic steatohepatitis (NASH) which can progress to cirrhosis and hepatocellular carcinoma (HCC). ${ }^{4}$ Fatty liver may be diagnosed if liver echogenicity exceeds that of renal cortex and spleen and there is attenuation of the ultrasound wave, loss of definition of the diaphragm, and poor delineation of the intrahepatic architecture. However this finding is not specific and cannot be used to diagnose NASH. Its sensitivity range from $60-100 \%$ and its specificity from $77-95 \%$ in detecting fatty infiltration of the liver. ${ }^{5}$

AST is a hepatic transaminase that plays a role in diagnosis of steatohepatitis. Up to $3.6 \%$ of people in the United 
States have asymptomatic increase in AST. $^{6}$ In Asian studies, AST is considered as an independent marker for severity of hepatic fibrosis if it is at least twice as much as the maximum normal value. ${ }^{7}$

The AST/ALT ratio is approximately 0.8 in normal subjects. The AST is greater than the ALT in alcoholic hepatitis and a ratio greater than 2:1 is highly suggestive of this disorder. A ratio >1.0 may also suggest the presence of cirrhosis in patients with chronic viral hepatitis. ${ }^{8}$

ALT is a marker of hepatic steatosis or hepatitis ${ }^{9}$ and $\mathrm{NASH}$ has been associated with slight elevation of liver enzymes ${ }^{10}$.Patients typically present with asymptomatic serum aminotransferase elevations of 2-3 times the normal $^{11}$.This was also explored by Pulzi et al 2011,12 where majority had mild elevation but less than 5 times upper normal limit and exists in all degree of NAFLD. But Alam et al 2013 showed serum alanine aminotransferase levels were not able to predict NASH. ${ }^{13}$

NASH has been associated with slight elevation of liver enzymes mostly ALT and Gamma-glutamyl transferase $(\mathrm{GGT})^{10}$. Excess deposition of fat in the liver is associated with an elevated serum GGT and insulin resistance. ${ }^{14}$ An increased GGT level is a risk factor for advanced fibrosis in NAFLD ${ }^{15}$ and with weight loss, a decrease in GGT activity is predictive of improved lobular inflammation and fibrosis of liver.

Liver biopsy remains the gold standard for the diagnosis of non-alcoholic steatohepatitis, which allows us to differentiate the simple steatosis from non-alcoholic steatohepatitis. ${ }^{16}$ There are practical limitations, including invasiveness, rare but potentially life-threatening complications ,like- risk of bleeding, allergic reaction caused by local anesthetics, advanced age, poor acceptability, sampling variability and cost. Furthermore, due to the epidemic proportion of individuals with nonalcoholic fatty liver disease worldwide, liver biopsy evaluation is impractical, and non-invasive assessment for the diagnosis of non-alcoholic steatohepatitis and fibrosis is needed.

The alanine aminotransferase (ALT) is a useful tool for non-invasive and available marker for assessment of non-alcoholic steatohepatitis.

\section{MATERIALS AND METHODS}

It was a hospital based observational study. The study was carried out for a period of 2 years in Department of Hepatology, Bangabandhu Sheikh Mujib Medical
University (BSMMU), Dhaka, Bangladesh. Patients of NAFLD attending at Hepatology department were selected as study population. We conduct fifty NAFLD patients for biochemical parameters, liver biopsy and NAS score evaluation in considering the exclusion and inclusion criteria. NAS score was constructed according to Kleiner et al. (2005) with steatosis (0-3), lobular inflammation (0-3), hepatocellular ballooning (0-2), and a separate fibrosis staging (0-4). The proposed NAS was the sum of steatosis, lobular inflammation, and hepatocellular ballooning. NAS is a strong scoring system. NAS of greater than or equal to

5 correlated with diagnosing of NASH and biopsy with scoring of 1 to 4 were diagnosed as simple steatosis. Patient's inclusion criteria were ultrasonographical evidence of fatty liver and patients from 18 to 60 years. Exclusion criteria were significant alcohol intake (AASLD) Practice guideline 2018, significant alcohol consumption be defined as $>21$ standard drinks per week in men and $>14$ standard drinks per week in women over 2 years period), viral hepatitis (HBV, HCV), Wilson's disease, autoimmune liver diseases, hereditary haemo- chromatosis, primary biliary cirrhosis, cirrhosis of liver, pregnancy, co-morbid conditions (COPD, CRF, cardiac failure), hypothyroidism, consumption of drugs causing fatty change in liver (steroid, oral contraceptive pill, tamoxifen, amiodarone, diltiagem, protease inhibitor).

Liver biopsy was done in the department of Hepatology, BSMMU by Trucut liver biospy needle $14 \mathrm{~F} 15 \mathrm{~cm}$. The tissue was processed at the Department of Pathology, by standard protocol in automatic tissue processor (BAVIMED 2050, BAVIMED Laborgeneratebau GmBH, Birkeau, Germany). The processed tissue was then properly embedded on the melted paraffin for making blocks and sections. The sections were stained with hematoxylin and eosin for microscopic examination. The ALT was measured by CI 4100 Architect plus autoanalizer (Abbott, USA) by liquid reagent pyridoxal-5- phosphate. After receiving the liver biopsy report, they were grouped as non-alcoholic steatohepatitis and simplesteatosis. Consecutive 25 non-alcoholic steatohepatitis patients and 25 simple steatosis patientsconfirmed by liver biopsy were included in this study.

\section{STATISTICAL ANALYSIS}

All data were presented as mean \pm SD and were analyzed by SPSS (version 16). The qualitative data were analyzed by Chi-squared test and the quantitative data were analyzed by student's t-test. 
Performance of the test were assessed by sensitivity and specificity test. Statistically significant result were considered when $\mathrm{p}$ value $<0.05$.

\section{ETHICAL CONSIDERATION}

Ethical clearance for the study was taken from the Institutional Review Board of BSMMU prior to the commencement of this study. Approval paper was given by $75^{\text {th }}$ IRB, BSMMU meeting held on $30^{\text {th }}$ novemember 2014. ( No. BSMMU/2014/13573).

\section{RESULTS}

Fifty (50) patients were analysed. Twenty five were NASH and twenty five were simple steatosis. ALT in NASH group were $97.0 \pm 51.5 \mathrm{IU} / \mathrm{L}$ and insimple steatosis group were $55.5 \pm 28.6 \mathrm{IU} / \mathrm{L}$. Overall, twenty six (52\%) had normal ALT.

Table-I: Distribution of the study patients by baseline characteristics $(\mathbf{n}=50)$

\begin{tabular}{|l|c|c|}
\hline Variables & Mean \pm SD & Min-Max \\
\hline Age (years) & $40.8 \pm 9.2$ & $25.0-60.0$ \\
Weight $(\mathrm{kg})$ & $64.5 \pm 9.2$ & $45.0-90.0$ \\
\hline Height $(\mathrm{cm})$ & $158.4 \pm 8.6$ & $145.0-182.0$ \\
\hline BMI $\left(\mathrm{kg} / \mathrm{m}^{2}\right)$ & $25.7 \pm 4.0$ & $18.2-36.5$ \\
\hline Waist circumference (cm) & $95.9 \pm 9.5$ & $76.0-122.0$ \\
\hline $\begin{array}{l}\text { Systolic blood pressure } \\
\text { (mm of Hg) }\end{array}$ & $129.2 \pm 14.6$ & $100.0-160.0$ \\
\hline $\begin{array}{l}\text { Diastolic blood pressure } \\
\text { (mm of Hg) }\end{array}$ & $80.6 \pm 7.0$ & $70.0-100.0$ \\
\hline Platelet count (-x109/L) & $315.4 \pm 69.6$ & $130.0-500.0$ \\
\hline Fasting blood sugar (mmol/L) & $6.2 \pm 2.6$ & $3.7-15.3$ \\
\hline 2HABF (mmol/L) & $9.5 \pm 4.4$ & $5.1-24.7$ \\
\hline Total cholesterol (mg/dl) & $205.0 \pm 44.8$ & $118.0-329.0$ \\
\hline LDL (mg/dl) & $122.8 \pm 39.2$ & $42.0-212.0$ \\
\hline HDL (mg/dl) & $38.7 \pm 9.3$ & $21.0-63.0$ \\
\hline TG (mg/dl) & $215.9 \pm 107.4$ & $58.0-441.0$ \\
\hline AST (U/L) & $44.4 \pm 28.2$ & $19.0-124.0$ \\
\hline ALT (U/L) & $76.2 \pm 47.4$ & $19.0-259.0$ \\
\hline AST/ALT & $0.6 \pm 0.2$ & $0.3-1.5$ \\
\hline HOMA-IR & $2.4 \pm 1.7$ & $0.4-8.5$ \\
\hline GGT (U/L) & $61.7 \pm 41.4$ & $12.0-209.0$ \\
\hline Serum ferritin (uggm/L) & $121.4 \pm 101.6$ & $14.2-573.2$ \\
\hline
\end{tabular}

Table-II : Clinical and laboratory characteristics of study patients in two group ( $\mathrm{n}=50$ )

\begin{tabular}{|c|c|c|c|}
\hline Variables & $\begin{array}{c}\text { NASH } \\
(\mathrm{n}=25) \\
\text { Mean } \pm \text { SD }\end{array}$ & $\begin{array}{c}\text { Simple } \\
\text { steatosis } \\
(\mathrm{n}=25) \\
\text { Mean } \pm \mathrm{SD}\end{array}$ & $\begin{array}{c}\mathrm{P} \\
\text { Value }\end{array}$ \\
\hline Age (years) & $41.8 \pm 10.7$ & $39.7 \pm 7.5$ & $0.425 \mathrm{~ns}$ \\
\hline Weight (kg) & $65.6 \pm 8.6$ & $63.3 \pm 9.7$ & $0.444 \mathrm{~ns}$ \\
\hline Height (cm) & $159.2 \pm 9.1$ & $157.7 \pm 8.3$ & $0.545 \mathrm{~ns}$ \\
\hline BMI (kg/m2) & $26.0 \pm 3.9$ & $25.5 \pm 4.0$ & $0.656 \mathrm{~ns}$ \\
\hline $\begin{array}{l}\text { Waist circumference } \\
(\mathrm{cm})\end{array}$ & $97.9 \pm 9.0$ & $93.9 \pm 9.8$ & $0.139 \mathrm{~ns}$ \\
\hline $\begin{array}{l}\text { Systolic blood pressure } \\
(\mathrm{mm} \text { of } \mathrm{Hg})\end{array}$ & $129.8 \pm 16.9$ & $128.6 \pm 12.2$ & $0.774 \mathrm{~ns}$ \\
\hline $\begin{array}{l}\text { Diastolic blood pressure } \\
(\mathrm{mm} \text { of } \mathrm{Hg})\end{array}$ & $80.2 \pm 7.8$ & $81.0 \pm 6.1$ & $0.688 \mathrm{~ns}$ \\
\hline $\begin{array}{l}\text { Platelet count } \\
(\mathrm{x} 109 / \mathrm{L})\end{array}$ & $303.1 \pm 68.7$ & $327.8 \pm 66.8$ & $0.203 \mathrm{~ns}$ \\
\hline FBS (mmol/L) & $6.6 \pm 2.8$ & $5.9 \pm 2.2$ & $0.330 \mathrm{~ns}$ \\
\hline $2 \mathrm{HABF}(\mathrm{mmol} / \mathrm{L})$ & $10.0 \pm 4.2$ & $9.1 \pm 4.7$ & $0.478 \mathrm{~ns}$ \\
\hline $\begin{array}{l}\text { Total cholesterol } \\
(\mathrm{mg} / \mathrm{dl})\end{array}$ & $210.0 \pm 48.7$ & $199.9 \pm 38.4$ & $0.419 \mathrm{~ns}$ \\
\hline LDL (mg/dl) & $126.0 \pm 40.5$ & $119.6 \pm 36.7$ & $0.561 \mathrm{~ns}$ \\
\hline HDL (mg/dl) & $40.7 \pm 9.1$ & $36.6 \pm 8.9$ & $0.113 \mathrm{~ns}$ \\
\hline TG (mg/dl) & $209.0 \pm 95.9$ & $222.8 \pm 116.2$ & $0.649 \mathrm{~ns}$ \\
\hline $\operatorname{AST}(\mathrm{U} / \mathrm{L})$ & $55.2 \pm 30.1$ & $33.6 \pm 20.0$ & $0.004 \mathrm{~s}$ \\
\hline ALT (U/L) & $97.0 \pm 51.5$ & $55.5 \pm 28.6$ & $0.001 \mathrm{~s}$ \\
\hline AST/ALT & $0.6 \pm 0.2$ & $0.7 \pm 0.3$ & $0.171 \mathrm{~ns}$ \\
\hline HOMA-IR & $2.4 \pm 1.9$ & $2.3 \pm 1.6$ & $0.841 \mathrm{~ns}$ \\
\hline GGT (U/L) & $73.6 \pm 48.6$ & $49.9 \pm 25.4$ & $0.035 \mathrm{~s}$ \\
\hline $\begin{array}{l}\text { Serum ferritin } \\
(\mu \mathrm{gm} / \mathrm{L})\end{array}$ & $139.4 \pm 124.5$ & $103.5 \pm 69.9$ & $0.214 \mathrm{~ns}$ \\
\hline
\end{tabular}

In NASH group $64 \%$ of raised ALT had NASH . In Non-NASH group $16 \%$ of raised ALT had no NASH. There was significant difference in the NAFLD activity score for diagnosing NASH between elevated and normal ALT ( $P$ value 0.001 ).

\section{ALT of the study patients}

Mean ALT was found 97.0 $\pm 51.5 \mathrm{U} / \mathrm{L}$ in NASH group and $55.5 \pm 28.6 \mathrm{U} / \mathrm{L}$ in simple steatosis group. The mean ALT was statistically significant $(\mathrm{p}$ value $=0.001)$ between two groups. 
Table-III Distribution of the study patients according to ALT ( $n=50)$

\begin{tabular}{|l|c|c|c|c|c|}
\hline \multirow{2}{*}{ ALT (U/L) } & \multicolumn{2}{|c|}{ NASH (n=25) } & \multicolumn{2}{c|}{ Simple steatosis (n=25) } & \multirow{2}{*}{ P value } \\
\cline { 2 - 5 } & $\mathrm{N}$ & $\%$ & $\mathrm{n}$ & $\%$ & \\
\hline$\leq 65$ & 8 & 32.0 & 17 & 68.0 & $0.001^{\mathrm{s}}$ \\
\hline $66-100$ & 6 & 24.0 & 6 & 24.0 & \\
\hline$>100$ & 11 & 44.0 & 2 & 8.0 & \\
\hline Mean \pm SD & 97.0 & \pm 51.5 & 55.5 & \pm 28.6 & \\
\hline
\end{tabular}

$s=$ significant

Table-IV : Distribution of NAFLD activity score or NAS scoreand ALT level $(\mathbf{n}=50)$

\begin{tabular}{|l|c|c|c|c|c|}
\hline \multicolumn{2}{|c|}{} & Liver biopsy & $\begin{array}{c}\text { Simple } \\
\text { steatosis }\end{array}$ & $\begin{array}{c}\text { Non-alcoholic } \\
\text { steatohepatitis }\end{array}$ & Total \\
\hline \multirow{3}{*}{ ALT } & $\begin{array}{c}\text { Normal } \\
(<65)\end{array}$ & $\mathrm{n}$ & 17 & 8 & 25 \\
& High & $68.00 \%$ & $32.00 \%$ & $100.00 \%$ \\
\cline { 2 - 6 } & $(>65)$ & $\mathrm{n}$ & 8 & 17 & 25 \\
& & $\mathrm{n}$ & $32.00 \%$ & $68.00 \%$ & $100.00 \%$ \\
\hline Total & $\mathrm{n}$ & 25 & 25 & 50 \\
& & & $50.00 \%$ & $50.00 \%$ & $100.00 \%$ \\
\hline
\end{tabular}

NAFLD activity score=NAS, Simple steatosis= NAFLD activity score 1-4, Non-alcoholic steatohepatitis $($ NASH $)=$ NAFLD activity score 5 or more.

Table-V : Person corelation between NAFLD activity score and ALT level $(\mathbf{n}=50)$

\begin{tabular}{|l|c|c|}
\hline Statistics & Value & 95\% CI \\
\hline Sensitivity & $68.00 \%$ & $46.50 \%$ to $85.05 \%$ \\
\hline Specificity & $68.00 \%$ & $46.50 \%$ to $85.05 \%$ \\
\hline Positive Predictive Value & $68.00 \%$ & $53.05 \%$ to $79.98 \%$ \\
\hline Negative Predictive Value & $68.00 \%$ & $53.05 \%$ to $79.98 \%$ \\
\hline
\end{tabular}

Pearson correlation between NAFLD activity score (NAS) score and alanine aminotransferase (ALT) level is 0.321 which is statistically significant $(\mathrm{p}<0.05)$.

\section{DISCUSSION}

Non-alcoholic fatty liver disease has been shown to be independently associated with increased overall, liver-related and cardiovascular mortality. ${ }^{17}$ Although the liver-related but not cardiovascular, mortality is higher in patients with non-alcoholic steatohepatitis compared with simple steatosis. ${ }^{17}$ Itis suggesting that progressive liver disease is mostlyconfined to non-alcoholic steatohepatitis.

Non-alcoholic fatty liver disease encompasses a spectrum of conditions ranging from simple steatosis to nonalcoholic steatohepatits (NASH), fibrosis and end stage liver disease by Ludwig et al $1980^{18}$. Hepatic steatosis is a manifestation of excessive triglyceride accumulation in the liver. The major sources of triglycerides are from fatty acids stored in adipose tissue and fatty acids newly made within the liver through denovo lipogenesis ${ }^{19}$.

The progression of NAFLD to its advanced stages is associated with significant morbidity in approximately $20 \%$ of patients, including complications such as gastro-oesophageal varices, ascites, liver failure, 
hepatopulmonary syndrome and encephalopathy. ${ }^{20}$ Furthermore, greater than $20 \%$ of NAFLD patients may develop cirrhosis over their lifetime according to a study by Matteoni et al. ${ }^{21}$ Of the patients who develop cirrhosis, $30-40 \%$ may suffer liver-related mortality within a 10-year period. $^{22}$ Therefore, recognizing patients with NASH and advanced fibrosis early in the disease spectrum is essential not only in managing but also in preventing further progression to cirrhosis and HCC, and its related complications.

In this study sixteen percent $(16 \%)$ of patients with normal ALT levels had evidence of NASH.Contrarily,sixteen percent of the patients with elevated ALT did not have NASH. NASH was present in $59 \%$ of patients with normal ALT in a recent study by Fracanzani et al. ${ }^{23}$, whereas the rate of NASH in patients with normal ALT was $2.9 \%$ by Lee et al. ${ }^{24}$ This difference in rate of NASH in normal ALT patients may be multifactorial.

ALT level is often considered by many clinicians as an easily accessible surrogate marker for evaluating underlying liver disease activity and severity of liver injury. ${ }^{25}$ Another study suggesting normal and elevated ALT levels do not correlate with the severity of NAFLD. ${ }^{26}$

Serum ALT level above the $65 \mathrm{U} / \mathrm{L}$ was present in $48 \%$ of NAFLD patients. Mean ALT differed significantly in $\mathrm{NASH}$ patients $(97.0 \pm 51.5 \mathrm{U} / \mathrm{L}$ in NASH versus $55.5 \pm$ 28.6 U/L in simple steatosis)(P value-0.001). Alam et al 2013 showed serum alanine aminotransferase levels were not able to predict $\mathrm{NASH}^{13}$.

\section{LIMITATION OF THE STUDY}

The present study evaluated predictive values of serum ALT and NAFLD activity score (NAS) to distinguish between nonalcoholic steatohepatitis (NASH) and simple steatosisin patients with NAFLD. This study presents some limitations such as small number of patients (50 patient), they were not selected randomly and only selected those patients who attended OPD, so there may be selection bias. All patients were collected in this study from a single tertiary level hospital that may not represent general population of the country. So, current study suffered from lack of multi-centric different ethnic category of patients.

\section{CONCLUSION}

This study found a significant difference in the NAFLD activity score for diagnosing NASH between elevated and normal ALT (P-value 0.001).

\section{RECOMMENDATION}

Alanine aminotransferase (ALT) level can be used as a non-invasive marker for the diagnosis of nonalcoholic steatohepatitis in non-alcoholic fatty liver disease patients.

\section{REFERANCES}

1. Eckel RH, Grundy SM, Zimmet PZ, The metabolic syndrome, Lancet. 2005; 365:1415-28.

2. Adams LA, Talwalkar JA. Diagnostic Evaluation of Nonalcoholic Fatty Liver Disease.J ClinGastroenterol. 2006; 40: 34-38.

3. Andrea ER. Nonalcoholic Fatty Liver Disease. In: Mark F, Lawrence SF, Lawrence JB, editors. Sleisenger and Fordtran's gastrointestinal and liver disease: pathophysiology/diagnosis/management. 9th ed. Philadelphia: Elsevier. 2010; 1401-13.

4. Pasumarthy L, Srour J, Nonalcoholic Steatohepatitis: a review of the literature and updates in management. South Med J.2010;103:547-50.

5. Caldwell SH, Al-Osmani AMS, Argo CK. Nonalcoholic fatty liver disease. In: Schiff ER, Maddrey WC, Sorrel MF, editors. Schiffs Disease of the liver.10th ed. Philadelphia.Lippincott Williams \& Wilkins. 2007;1117-681.

6. Ioannou GN, Boyko EJ, Lee SP. The prevalence and predictors of elevated serum aminotransferase activity in the United States in1999-2002. Am J Gastroenterol. 2006; 101: 76-82.

7. Fan JG, Saibara T, Chitturi S, Kim BI, Sung JJ, Chutaputti A. Whatare the risk factors and settings for non-alcoholic fatty liver diseasein Asia-Pacific? J GastroenterolHepatol.2007; 22: 794-800 .

8. Argo CK, Northup PG, Al-Osaimi AM, Caldwell SH.Systematic review of risk factors for fibrosis progression in non-alcoholic steatohepatitis. J. Hepatol.2009; 51: 371-79.

9. Angulo P, KeachJC, Batts KP, Lindor KD. Independent predictors of liver fibrosis in patients with nonalcoholic steatohepatitis.Hepatology.1999; 30: 1356-62.

10. Angulo P, Hui JM, Marchesini G. The NAFLD fibrosis score: A noninvasive system that identifies liver fibrosis in patients with NAFLD. Hepatology. 2007; 45: 846-54.

11. Annurad E, Shiwaku K, Nogi A, Kitajima K, Enkhmaa B, Shimono K, Yamane Y. The New BMI 
criteria for Asians by the Regional Office for the Western Pacific Region of WHO are suitable for the screening overweight to prevent metabolic syndrome in Elder Japanese Workers. J occup Health. 2003; 45: $335-43$.

12. Pulzi FBU, Cisternas RM, Murilo RR, Cristiane MF, Malheiros CA, Salles JE ,'New clinical score to diagnose non-alcoholic steatohepatitis in obese patients', Diabetology\& Metabolic Syndrome, 2011; 3: 3-8.

13. Alam S, Alam SMN, Chowdhury ZR, Alam Mahbubul, Kabir Jahangir, 'Nonalcoholic steatohepatitis in nonalcoholic liver disease patients of Bangladesh', World J Hepatol. 2013;5: 281-87.

14. Bayard M, Holt J, Boroughs E.Nonalcoholic fatty liver disease. Am Fam Physician. 2006; 73: 1961-1968.

15. Bellentanis S, Scaglioni F, Marinom, Bedogni G. Epidemiology of non-alcoholic fatty liver disease. Dig Dis. 2010; 28: 155-61.

16. Caldwell SH, Argo CK. Non-alcoholic Fatty Liver Disease and Nutrition. In: Sherlock's Diseases ofthe liver and biliary system. Dooley JS, Lok ASF,Burroughs AK, Heathcote EJ (eds). 12th ed. WestSussex, Wiley-Blackwell, 2011, pp 546-67.

17. Musso G, Gambino R, Cassader M, Pagano G. Meta-analysis: Natural history of non-alcoholic fatty liver disease (NAFLD) and diagnostic accuracy of non-invasive tests for liver disease severity. Ann Med. 2011; 43: 617-49.

18. Ludwig J, Viggiano TR, McGill DB, Oh BJ , 'Nonalcoholi steatohepatitis: Mayo Clinic experience with a hitherto unnamed disease', Mayo Clin Proc 1980; 55: 434-38.

19. Bugianesi E, Manzini P, D'AnticoS.Relative contribution of iron burden, HFE mutations, and insulin resistance to fibrosis in nonalcoholic fatty liver.Hepatology. 2004; 39: 179-87.

20. Bhala N, Angulo P, van der Poorten D, et al. The natural history of nonalcoholic fatty liver disease with advanced fibrosis or cirrhosis: an international collaborative study. Hepatology 2011; 54: 1208-16.

21. Matteoni CA, Younossi ZM, Gramlich T, et al. Nonalcoholic fatty liver disease: a spectrum of clinical and pathological severity. Gastroenterology 1999; 116: 1413-9.

22. McCullough AJ. The epidemiology and risk factors of NASH. In: Farrell GC, George J, Hall P, McCullough AJ, eds. Fatty Liver Disease: NASH and Related Disorders. Oxford (UK): Blackwell Publishing; 2005; 23-37.

23. Fracanzani AL, Valenti L, Bugianesi E, et al. Risk of severe liver disease in nonalcoholic fatty liver disease with normal aminotransferase levels: a role for insulin resistance and diabetes. Hepatology 2008; 48: 792-8.

24. Lee JY, Kim KM, Lee SG, et al. Prevalence and risk factors of non-alcoholic fatty liver disease in potential living liver donors in Korea: a review of 589 consecutive liver biopsies in a single center. J Hepatol 2007; 47: 239- 44 .

25. Alam S, Ahmad N, Mustafa G, et al. Evaluation of normalor minimally elevated alanine aminotransaminase, age and DNAlevel in predicting liver histological changes in chronichepatitis B. Liver Int 2011; 31: 824-30.

26. Siddharth Verma, Donald Jensen, John Hart, Smruti R. Mohanty, Predictive value of ALT levels for non-alcoholic steatohepatitis (NASH) and advanced fibrosis in non-alcoholic fatty liver disease (NAFLD). Liver Int. 2013; 33: 1398-1405. 